\title{
Investigations on the influence of process parameters on the structural evolution of ion beam sputter deposited chromium thin films
}

\author{
R. Balu ${ }^{\text {a }}$, A.R. Raju ${ }^{\text {b }}$, V. Lakshminarayanan ${ }^{\text {c }}$, S. Mohan ${ }^{\mathrm{a}, *}$ \\ ${ }^{a}$ Department of Instrumentation, Indian Institute of Science, Bangalore 560012, India \\ b Jawaharlal Nehru Centre for Advanced Scientific Research, Bangalore, India \\ ${ }^{\mathrm{c}}$ Raman Research Institute, Bangalore, India
}

\begin{abstract}
Chromium thin films are technologically important as underlayers for the deposition of cobalt-based magnetic films because of their good lattice match and adhesion. The structural orientation and morphology of the chromium under layers control the magnetic properties of the cobalt-based films deposited on them. Hence, optimization of the structure and properties of chromium under layers is essential for realizing magnetic thin films with desired properties. In this paper, we report the structural variation observed in chromium thin films deposited on silicon( $\left.\begin{array}{lll}1 & 0 & 0\end{array}\right)$ substrates deposited using Ion Beam Sputter Deposition (IBSD) technique. The influence of process parameters, such as ion beam current density, substrate temperature and the angle of incidence of the condensing species, on the structural transformation from (1 10$)$ orientation to $(200)$ orientation has been presented. The structural variation and morphological variations observed have been discussed based on the growth models and the energetics involved in the process.
\end{abstract}

Keywords: Chromium thin films; Ion Beam Sputter Deposition (IBSD); Oblique deposition

\section{Introduction}

The role of chromium $(\mathrm{Cr})$ underlayers with tailored structure in controlling the structural and magnetic properties of cobalt-based thin films have been known since 1970 [1]. As a result of this, deposition of chromium films have attained technological importance in the longitudinal magnetic recording field, where cobalt-based alloys are being used extensively. Being a bcc metal, $\mathrm{Cr}$ thin film prefers (11 10$)$ orientation on the plane of the surface, which is the plane of minimum energy. However, under certain process conditions, it also forms ( 200$)$ orientation, which is the plane of better match for cobalt-based alloys. In the preparation of Cr films, the structural transformation from (1 110$)$ to (2 000$)$ orientation has been the subject of focus in the recent past, in which the films were deposited by various techniques like evaporation [2-4], sputtering with various geometries [5-9],

\footnotetext{
* Corresponding author. Tel.: +91 802360 1143; fax: +91 8023600135 .

E-mail address: smohan@isu.iisc.ernet.in (S. Mohan).
}

ion plating [10], pulsed laser deposition (PLD) [11,12], etc. In general, in the preparation of $\mathrm{Cr}$ films higher substrate temperatures have favored [13] the structural transformation

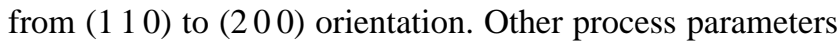
like operating pressure [7], epitaxy [14], thermalisation distance [6], substrate biasing [5], secondary ion assistance [12], ion irradiation [3], nitrogen addition [15], etc., have also been found to influence the structural transformation in several ways, in addition to the substrate temperature.

The distribution of crystallographic orientations of the grains in polycrystalline films evolve through a number of kinetic processes [16]. The texture development in these films can take place during (a) pre-coalescence stage, (b) during coalescence, (c) during thickening of continuous films and (d) during post deposition annealing. In the deposition of $\mathrm{Cr}$ thin films, the texture development has been observed to happen in the pre-coalescence stage $[5,12,17]$ and based on the experimental observations, models were proposed for the texture development. Parker et al. [18] have used the evolutionary selection model put forth by Van der Drift [19] to 
explain the structural evolution. According to them, the difference in growth rates between different crystal faces of the grains on the surface is the cause for the variation in structural evolution. In another model, Feng et al. [5] have framed their formalism based on the surface energy minimization principle at the time when the crystallographic texture develops. According to them: (i) the crystallographic texture originates from the preferential orientations of islands, which are nucleated on the substrate surface before a continuous film forms and (ii) the crystallographic texture develops by the faster growth of grains with certain orientation after the film becomes a continuous film. They attributed the former mechanism to the (200) texture and the latter to the (110) texture. Though these models match with the experimental observations, they are more of qualitative nature in the selection of process parameters. The explanations for the structural variations are attributed to different parameters, such as substrate temperature, pressure, deposition rate, etc., by different investigators. However, it is necessary to look at the influence of all the process parameters and their overall effect on the evolution process to have a better understanding of the structural variation.

In this paper, we report the influence of process parameters on the structural evolution and transformation of ion beam sputter deposited chromium films. Ion Beam Sputter Deposition (IBSD) is known for its low pressure sputtering $\left(1 \times 10^{-4} \mathrm{mbar}\right)$ with independent control over the energy and flux. The beam consists of a well-collimated monoenergetic species where the angle of incidence of the beam over the target could be changed accordingly. This affects the spatial and energy distribution of the sputtered species considerably. Because of higher incident energy and oblique incidence, high energy reflected neutrals and ions are also inevitable which can potentially modify the film properties. It is also important to note that the sputtering yield is also dependent of the angle of incidence. These features make IBSD to be different from the conventional sputtering techniques [20].

\section{Experimental}

A $3 \mathrm{~cm}$ Kaufman type de ion source was used in the sputtering of $5 \mathrm{~cm}$ diameter chromium target (Angstrom Sciences) of purity $99.99 \%$. The target was mounted on a rotating feed thorough with a holder that can hold multiple targets [21]. The ion source and the target assembly were housed in a box type vacuum chamber evacuated using a cryo-rotary pump combination. The chamber could reach a base pressure better than $1 \times 10^{-6}$ mbar and the deposition was carried out at a pressure of $1 \times 10^{-4} \mathrm{mbar}$ of argon (99.999\%). The ion beam was incident on the target at an angle of $45^{\circ}$ with a beam energy of $1 \mathrm{keV}$ at different ion fluxes. A $5 \mathrm{~cm}$ diameter resistive type heater that can go up to a maximum temperature of $850^{\circ} \mathrm{C}$ was used to maintain the substrates at desired temperature. The heater, with a substrate to target distance of $7 \mathrm{~cm}$ was mounted on a slotted base plate to change the position accordingly. The films were deposited on $\operatorname{Si}\left(\begin{array}{lll}1 & 0 & 0\end{array}\right)$ wafers sliced to $1.5 \mathrm{~cm} \times 1.5 \mathrm{~cm}$ dimension. The samples were placed in three different positions, namely A-C with different angles of incidence $(\Psi) 10^{\circ}, 20^{\circ}$ and $30^{\circ}$ measured at the centre of the substrates with respect to the normal of the target and the arrangement is shown in Fig. 1. Films were deposited with different process parameters like deposition rate, film thickness, substrate temperature and angle of incidence.

The crystallographic structure and the average grain size of the deposited films were studied using a X-ray diffractometer with $\mathrm{Cu} \mathrm{K} \alpha$ radiation in the $\theta / 2 \theta$ configuration. The growth morphology was studied using cross-sectional scanning electron microscope (SEM) and the surface morphology was studied using scanning tunneling microscope (STM). Thickness measurements were carried out using step profilometer and were confirmed by SEM.

\section{Results and discussion}

Fig. 2 shows the XRD spectra of the films (position A) deposited at different deposition rates varied by varying ion fluxes for a fixed beam energy and deposition time. The deposition rates were varied from 3.5 to $15 \mathrm{~nm} / \mathrm{min}$ with a constant deposition time of $30 \mathrm{~min}$. From the spectra, it is seen that films corresponding to Fig. 2(a and b) with lower deposition rates and lower thicknesses show an amorphous nature whereas films (c-e) with higher deposition rate and higher thickness show a crystalline nature, with a peak corresponding to (1 110$)$ plane showing up in XRD spectra. Since the deposition rate and thickness are changing simultaneously in the above case, the structural evolution observed might have been induced by either the deposition rate or film thickness or both. To understand the structural evolution process more clearly, for further studies the deposition rate has been maintained constant at $15 \mathrm{~nm} / \mathrm{min}$ and films have been deposited with different thicknesses. Fig. 3 shows the XRD spectra for the films deposited (position A) with thicknesses ranging from 100 to $360 \mathrm{~nm}$. Film (a) with lower thickness of $100 \mathrm{~nm}$ shows a crystalline nature with a peak corresponding to (1 110$)$ orientation. As the film thickness increases (from Fig. 3(a-d)) the peak intensity increases indicating a better crystallization nature. Comparing the films of Fig. 2(a) of thickness $100 \mathrm{~nm}$ with a deposition rate of $15 \mathrm{~nm} / \mathrm{min}$ and the same thickness film in Fig. 3(a) deposited at a rate of $3.5 \mathrm{~nm} / \mathrm{min}$, it is clearly seen that for the films of same thickness films deposited at higher deposition rate are of crystalline nature. This indicates that it requires a critical deposition rate for realizing crystalline films whereas film thickness helps in improving the crystallization nature of the deposited films.

Observations from Figs. 2 and 3 indicate that the deposition rates play a crucial role in the structural evolution. When the deposition rates are low, the condensing species that starts nucleating have more time to reach surface energy equi- 


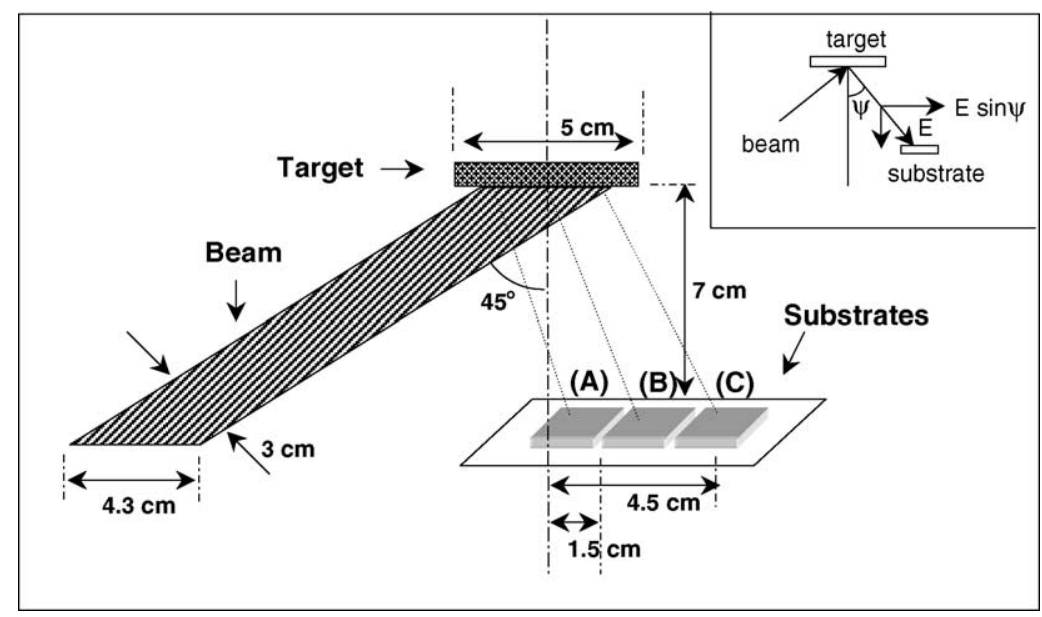

Fig. 1. Schematic of the sputtering arrangement and position of the samples. Inset shows the energy considerations in oblique deposition.

librium. However, the growth of nucleated islands depends on the mobility of the adatoms on the substrate surface and the kinetic energy of the condensing and bombarding particles. The low substrate temperature during the deposition, limits the mobility of the adatoms on the substrate surface, which prevent the islands from attaining equilibrium. In addition, the growing film may experience the bombardment of high energy species, which may effectively break the structural bonds, formed in the initial stages of film growth [5]. If the deposition rates are sufficiently high, the nucleated islands before attaining energy equilibrium start impinging each other forming a continuous film growth. The crystallization process starts after the impingement of the islands in this case. This leads to the formation of (110) orientation on the surface of the deposited film. This is evident from Fig. 3(a) where in the film with lower thickness shows a crystalline nature owing to its higher deposition rate compared to

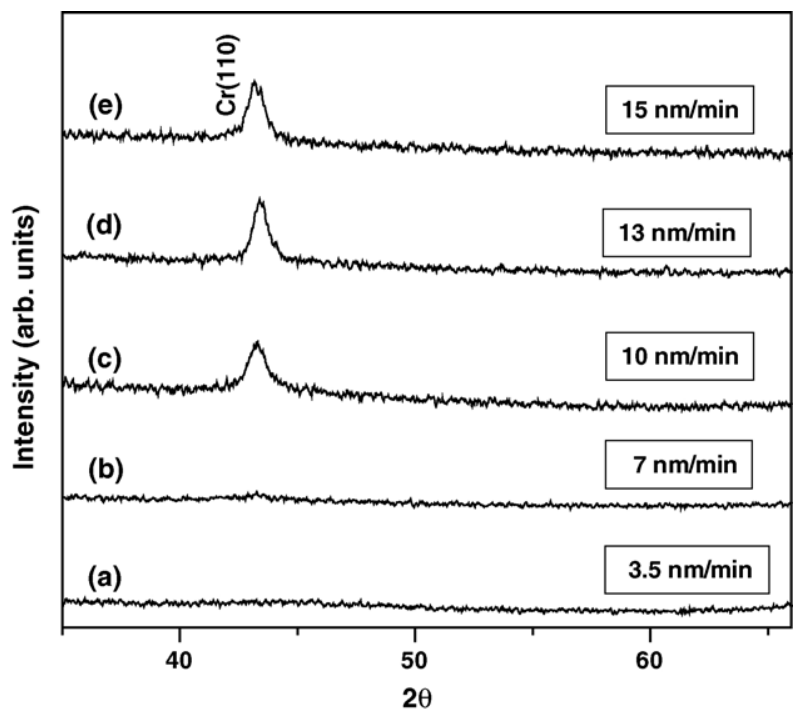

Fig. 2. XRD spectra of the samples deposited at different sputtering rates with a beam energy of $1 \mathrm{keV}$ and a deposition time of $30 \mathrm{~min}$.
Fig. 2(a) with the same thickness with low deposition rate. A similar result has been reported for the films deposited by PLD [12], in which this amorphous nature is seen to exist in lower deposition rates even for substrate temperatures as high as $200^{\circ} \mathrm{C}$. Hence, sufficiently high deposition rates are needed for the $\mathrm{Cr}$ films to form crystalline structure as observed.

Fig. 4 shows the XRD spectra of the films deposited (position A) with a deposition rate of $15 \mathrm{~nm} / \mathrm{min}$ at different substrate temperatures ranging from 25 to $700^{\circ} \mathrm{C}$. From the figure, it is seen that the (110) orientation peak observed at $25^{\circ} \mathrm{C}$ gets intensified with the increase in the substrate temperature. For the film deposited at $700^{\circ} \mathrm{C}$, the XRD spectra shows an intense peak corresponding to ( 1110$)$ orientation with a narrow full width at half maximum (FWHM) indicating a good crystalline nature of this film. Using the Scherer formula, the grain sizes have been calculated and they range from 10 to $20 \mathrm{~nm}$ as the substrate temperature increases from

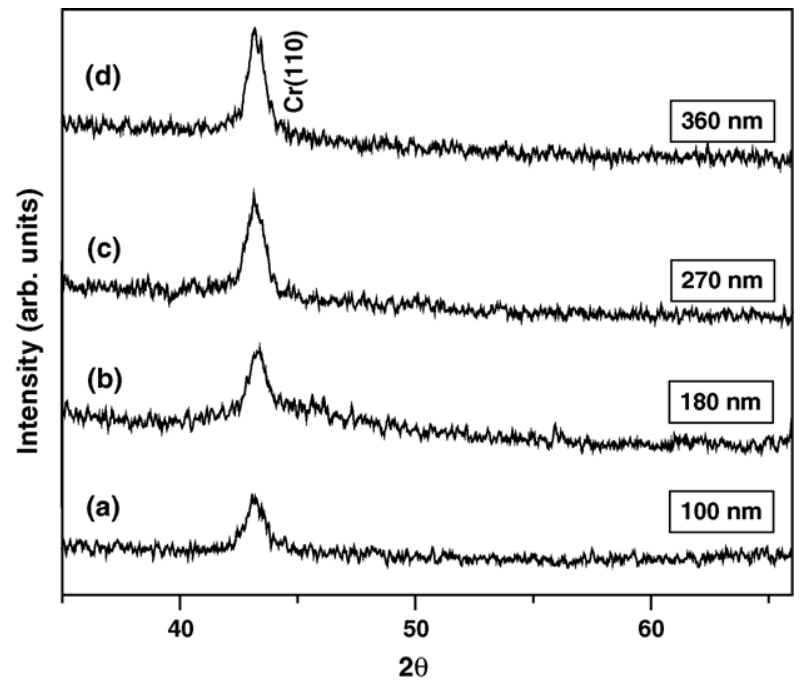

Fig. 3. XRD spectra of the films prepared at a deposition rate of $15 \mathrm{~nm} / \mathrm{min}$ for different thicknesses at room temperature. 


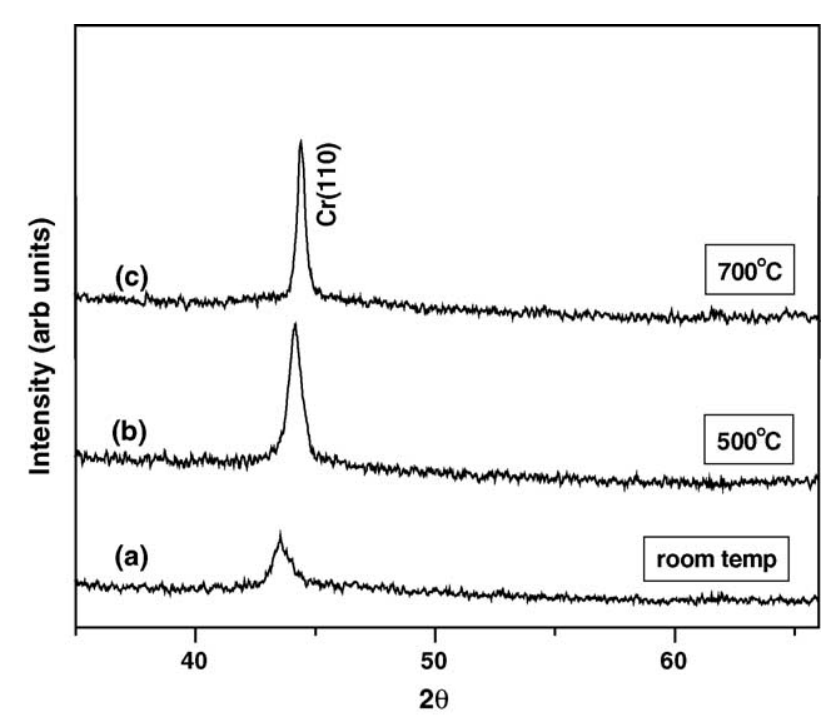

Fig. 4. XRD spectra of the films deposited at different substrate temperatures with a deposition rate of $15 \mathrm{~nm} / \mathrm{min}$ and for a time of $30 \mathrm{~min}$.

25 to $700^{\circ} \mathrm{C}$. It is worth to note here that the $\mathrm{Cr}(110)$ orientation sustains even at temperatures as high as $700{ }^{\circ} \mathrm{C}$ and there is no indication in XRD pattern to show the presence of (200) orientation. From the above results, we observe that the deposition rate, thickness and substrate temperature contribute to the crystallization improvement of (1 110$)$ orientation in the deposition of chromium films by IBSD.

In general, in the deposition of $\mathrm{Cr}$ thin films, structural transformation from (110) to (200) orientation has been observed to occur above substrate temperatures of $250^{\circ} \mathrm{C}$ in magnetron sputtering [5] and $350^{\circ} \mathrm{C}$ in the case of PLD [12], however with the influence of other process parameters. Here, for the films deposited at different substrate temperatures, which is shown in Fig. 4, the (110) orientation is observed to sustain even at substrate temperatures as high as $700^{\circ} \mathrm{C}$. As such the increase in substrate temperature helps in increasing the mobility of the adatoms. This promotes the surface diffusion [22] leading to the formation of island growth. As the substrate temperature increases, the minimum size of the critical stable nucleus also increases. At lower deposition rates, these nucleated islands preserve its island like character for higher thicknesses thus taking sufficiently longer time for the formation of continuous film. Here, comparatively high deposition rates have been used and this will basically favor more number of nucleation centers in the initial stages of growth. This may prevent the islands from reaching their stable critical size before they form the continuous film. This can lead to the film growth with $\left(\begin{array}{lll}1 & 1 & 0\end{array}\right)$ orientation even at higher substrate temperatures. It is also important to note that crystallites corresponding to minimum surface energies will grow at the expense of crystallites with higher surface energy. In this case, as the temperature increases, even the least probable formation of (200) oriented crystallites will get coalesced with the energetically favored $(110)$ oriented crystallites. In addition, the effect of high energy reflected species that can

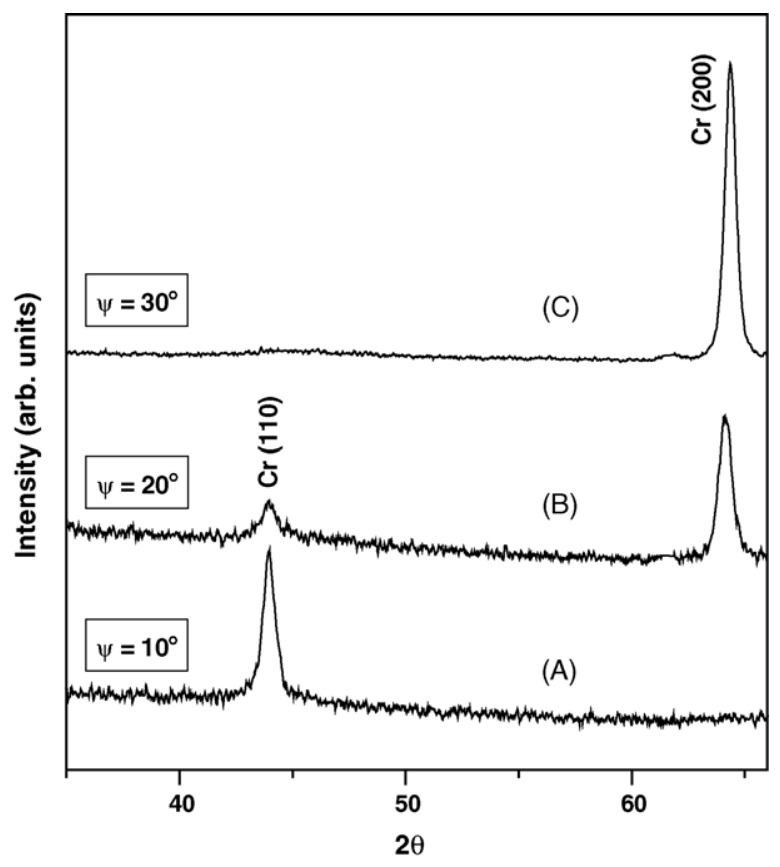

Fig. 5. XRD spectra of the samples deposited at different angles of incidence with a substrate temperature of $500^{\circ} \mathrm{C}$ and a deposition rate of $15 \mathrm{~nm} / \mathrm{min}$ at the target normal.

effectively break the islands is also to be considered for the survival of $\left(\begin{array}{lll}1 & 1 & 0\end{array}\right)$ orientation even at higher temperatures as is seen in low energy ion bombardments [12].

As substrate temperatures as high as $700^{\circ} \mathrm{C}$ did not favor the formation of (200) orientation, oblique incidence was considered as a tool to modify the initial growth conditions prevailing. In oblique incidence, the sputtered species condense on the substrate surface at a specified angle. This makes the condensing species to have higher mobility and exhibit self-shadowing effect [22] leading to a change in the film growth conditions. Fig. 5 shows the XRD spectra of the films deposited at a substrate temperature of $500^{\circ} \mathrm{C}$ at three different positions A-C. From the XRD spectra, it is seen that film $\mathrm{A}$, which is close to the normal incidence shows (1 10$)$ as the preferred orientation, film B with an angle of $20^{\circ}$ shows a polycrystalline nature with $\left(\begin{array}{lll}1 & 1 & 0\end{array}\right)$ and (200) orientations and film $\mathrm{C}$ with an angle of $30^{\circ}$ shows a preferential orientation of $(200)$. Film thicknesses measured at the center of the films vary from $300 \mathrm{~nm}$ for the near normal incidence to $150 \mathrm{~nm}$ for the film deposited at $30^{\circ}$.

The concept of oblique deposition has long been used in the deposition of magnetic thin films [23] in enhancing their magnetic properties and self-shadowing has been found to be the crucial parameter [24] in the development of thin film growth morphologies as explained by Dirks and Leamy [25]. This technique also called as glancing angle deposition (GLAD) has also been used to deposit films of a new class of engineered columnar thin films [26,27]. Ableman and Lodder [22] have reviewed the oblique evaporation and report that the surface diffusion altered by the surface momentum 
of the adatoms and self-shadowing determines the texture formation and columnar inclination. In the oblique incidence followed here in addition to surface momentum and selfshadowing, the ejected particles show an angular distribution making the spatial distribution to vary. With the angle of incidence of the beam maintained at $45^{\circ}$, the film thicknesses show a decreasing trend as we move from the target normal. But in the near normal incidence of the condensing species, under this configuration film uniformity is preserved in an area of $2 \mathrm{~cm}^{2}$, which however starts decreasing when moved further away. Hence, the samples away from the near normal incidence have lower deposition rate with higher momentum available for the adatoms along the surface initially. At higher substrate temperatures, these conditions favor the formation of island growth and sufficiently longer time will be available for the grains to reach their surface energy equilibrium leading to the formation of $(200)$ orientation as seen in sample $C$. In the case of film $B$, where the angle of impingement is $20^{\circ}$ that is slightly away from the normal, one can see the presence of peak corresponding to (200) along with (1 10$)$, indicating the enhancement in the structural orientation from the oblique incidence. The preferential orientation of (200) planes seen in film $\mathrm{C}$ has however needed substrate temperatures as high as $500^{\circ} \mathrm{C}$. It is also worth to mention that the films deposited at lower deposition rates with higher substrate temperatures at position A showed only (1 110$)$ orientation eliminating the role of deposition rate at position $\mathrm{A}$. Hence, the formation of (200) should be seen as the combined effect of self-shadowing added with surface diffusion that persist due to low sputtering rate, oblique deposition and high substrate temperature.

To understand the influence of the angle of incidence over the surface morphology, STM was employed and the surface morphologies have been studied for the samples deposited at $500{ }^{\circ} \mathrm{C}$ with different angles of incidence. The surface morphologies as observed for these films are shown in Fig. 6. For the film A, the surface morphology shows random grain orientation. Film B, with an angle of incidence of $20^{\circ}$, the morphology shows a mixed nature with partial arrangement of grains. In film $\mathrm{C}$ with $(200)$ preferential orientation, the morphology shows a ripple formation. The ripple topography observed in the sample at position $\mathrm{C}$ should be considered as the effect of energetic particle bombardment during the film growth process. The bombarding energetic species produces a collision cascade beneath the surface of the film and resputters a part of it. The surface is not smooth at the atomic level due to crystallization and resputtering. At the grooves of the surface, these collision cascades overlap with each other and enhance the resputtering yield. On the other hand, at the cusps of the surface the overlapping is not as effective and the resputtering is lower and hence a ripple topography is observed at higher energy ion bombardment [20,21]. The roughness of the films decreases from 10 to $4 \mathrm{~nm}$ as we move from sample A to sample $\mathrm{C}$.

Fig. 7 shows the cross-sectional morphology of the $\mathrm{SmCo} / \mathrm{Cr} / \mathrm{Si}$ stack deposited with an angle of incidence of
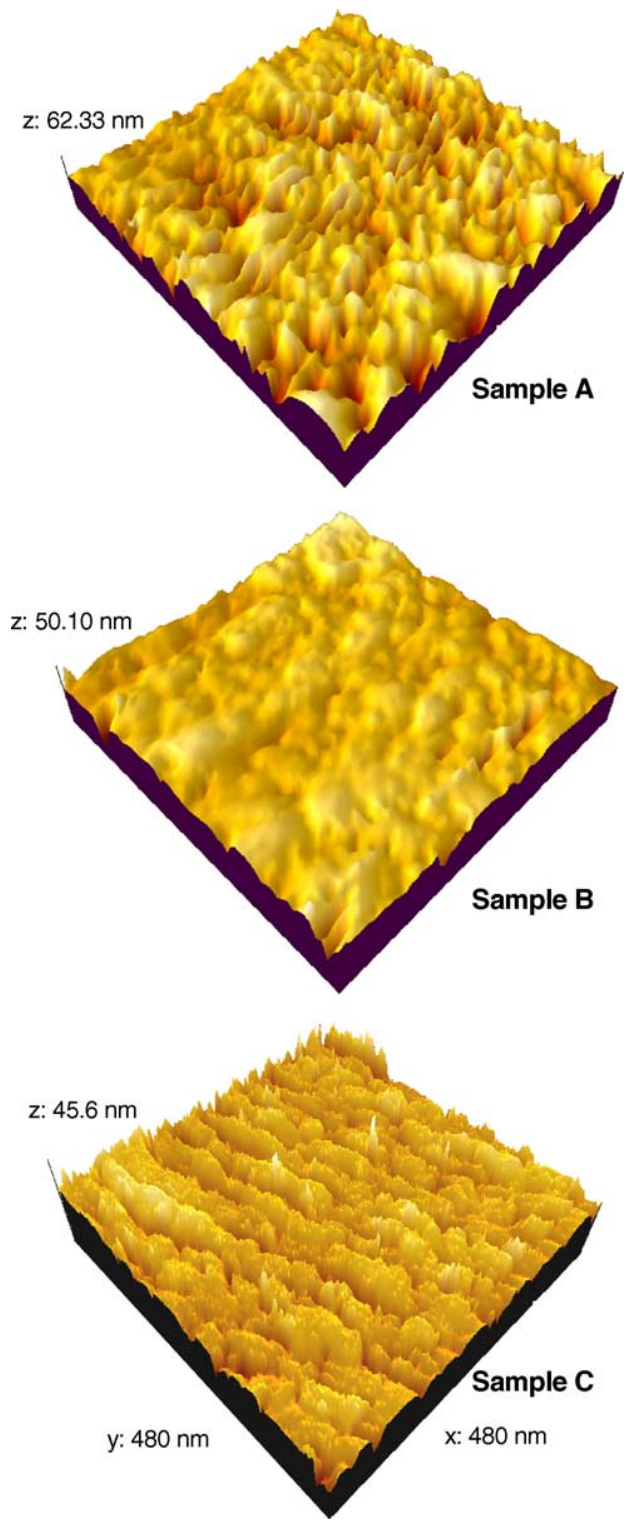

Fig. 6. Surface morphology as seen by STM for the films deposited at a substrate temperature of $500{ }^{\circ} \mathrm{C}$ with different angles of incidence.

$10^{\circ}$ (position A). Here, the chromium film shows a columnar morphology with uneven column structure and small column tilt. At the interface near the silicon substrate the morphology shows columns of smaller diameter, which increases in size as the film thickness increases. The films deposited at position A show a (1 110$)$ orientation indicating that the crystallization occurs after the coalescence of the islands, which have formed initially. At higher substrate temperatures, even if a (200) texture develops initially, as long as some grains have the $(110)$ orientation, the $(110)$ orientation will win out, as the film grows thicker [5]. Hence, broadening of the columns with the increase in film thickness is expected. The column tilt observed here should be considered as the effect of self-shadowing, corresponding to the angle of incidence of $10^{\circ}$ [22]. 


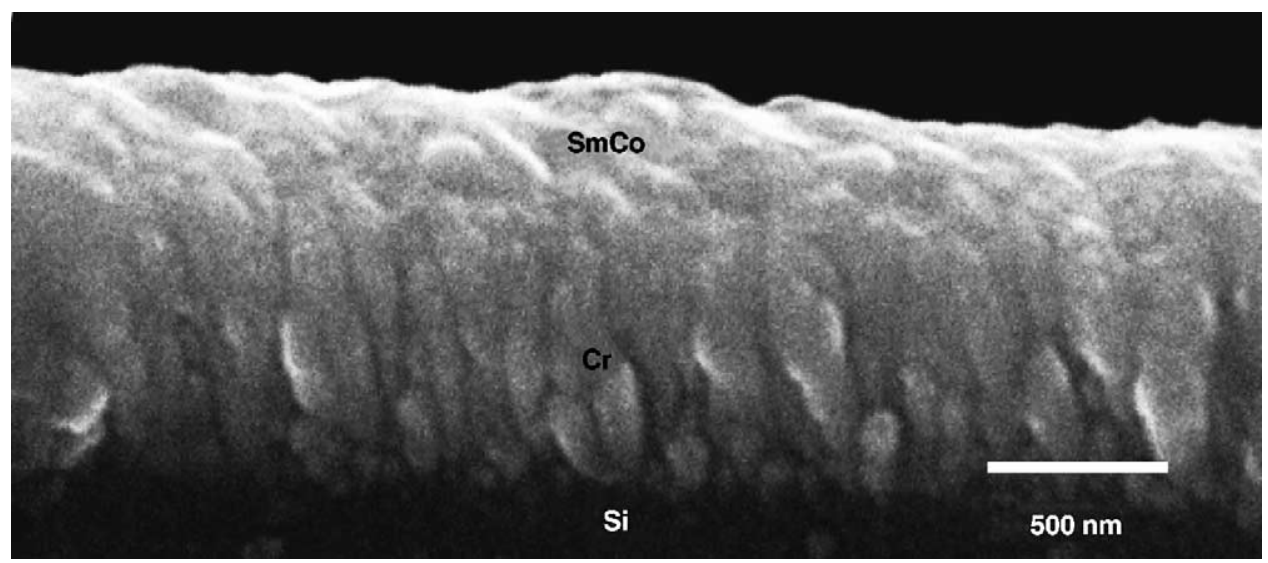

Fig. 7. SEM cross-sectional view showing the columnar morphology of the $\operatorname{Cr}\left(\begin{array}{lll}1 & 1 & 0\end{array}\right)$ in the $\mathrm{SmCo} / \mathrm{Cr} / \mathrm{Si}$ stack.

\section{Conclusion}

Chromium films have been deposited by IBSD technique with varied process parameters. The energetics involved in the process has been observed as the important criteria that influence the structural evolution. Deposition rate has been found to play a major role in the initial structure formation indicating the necessity of a critical deposition rate. It has been observed that $\left(\begin{array}{lll}1 & 10\end{array}\right)$ orientation sustains even at higher substrate temperatures as high as $700^{\circ} \mathrm{C}$. The structural transformation of (110) to (200) orientation occurs when the process parameters favor the formation of island growth, which was carried out using oblique incidence technique. With higher angle of incidence, the film shows (200) preferential orientation, which is considered to be the plane of better lattice match to Co-based alloys. The surface morphology shows a ripple nature with comparatively lower surface roughness. From the above investigations, it is clear that the energetics of the process controlled by various factors, such as deposition rate, substrate temperature and film thickness associated with oblique incidence, plays the major role in the structural transformation from (1 110$)$ to $(200)$ orientation in Cr thin films.

\section{References}

[1] J. Daval, D. Randet, IEEE Trans. Magn. MAG-6 (1970) 768-773.

[2] V. Agarwal, V.D. Vankar, K.L. Chopra, J. Vac. Sci. Technol. A 6 (1988) 2341-2343.

[3] N. Kuratani, A. Ebe, K. Ogata, J. Vac. Sci. Technol. A 16 (1998) 2489.

[4] A.K. Kulkarni, L.C. Chang, Thin Solid Films 301 (1997) 17-22.
[5] Y.C. Feng, D.E. Laughlin, D.N. Lambeth, J. Appl. Phys. 76 (1994) $7311-7316$

[6] R.A. Miller, H.J. Holland, Thin Solid Films 298 (1997) 182-186.

[7] T. Kawanabe, J. Park, M. Naoe, Mater. Sci. Eng. A 134 (1991) 1305-1308.

[8] Z.B. Zhao, S.M. Yalisove, Z.U. Rek, J.C. Bilello, J. Appl. Phys. 92 (2002) 7183-7192.

[9] Y. Gotoh, Y. Taga, J. Appl. Phys. 67 (1990) 1030-1036.

[10] D.D. Wang, T. Oki, J. Vac. Sci. Technol. A 8 (1990) 3163-3167.

[11] A. Ishikawa, K. Tanahashi, Y. Yahisa, Y. Hosoe, Y. Shiroishi, J. Appl. Phys. 75 (1994) 5978-5980.

[12] M. Shima, C.A. Ross, J. Appl. Phys. 93 (2003) 945-950.

[13] D.P. Ravipati, W.G. Haines, J.L. Dockendorf, J. Vac. Sci. Technol. A 5 (1987) 1968-1970.

[14] E.E. Fullerton, J.S. Jiang, C. Rehm, C.H. Sowers, S.D. Bader, J.B. Patel, X.Z. Wu, Appl. Phys. Lett. 71 (1997) 1579-1581.

[15] V. Guilbaud-Massereau, A. Celerier, J. Machet, Thin Solid Films 258 (1995) 185-193.

[16] C.V. Thompson, R. Carel, Mater. Sci. Eng. B 32 (1995) 211-219.

[17] M. Hu, S. Noda, H. Komiyama, J. Appl. Phys. 93 (2003) 93369344.

[18] M.A. Parker, K.E. Johnson, C. Hwang, A. Bermea, IEEE Trans. Magn. 27 (1991) 4730-4732.

[19] A. Van der Drift, Philips Res. Rep. 22 (1967) 267-288.

[20] J.J. Cuomo, S.M. Rossnagel, H.R. Kaufman (Eds.), Handbook of Ion Beam Processing Technology, Noyes Publications, New Jersey, 1989.

[21] S. Balaji, P.V. Satyam, V. Lakshminarayanan, S. Mohan, Nucl. Instrum. Methods Phys. Res. B 217 (2004) 423-428.

[22] L. Abelmann, C. Lodder, Thin Solid Films 305 (1997) 1-21.

[23] T.G. Knorr, R.W. Hoffman, Phys. Rev. 113 (1959) 1039-1046.

[24] J.M. Nieuwenhuizen, H.B. Haanstra, Philips Tech. Rev. 27 (1966) $87-91$.

[25] A.G. Dirks, H.J. Leamy, Thin Solid Films 47 (1977) 219-233.

[26] K. Robbie, J.C. Sit, M.J. Brett, J. Vac. Sci. Technol. B 16 (1998) $1115-1122$.

[27] R. Messier, V.C. Venugopal, P.D. Sunal, J. Vac. Sci. Technol. A 18 (2000) 1538-1545. 